\title{
Identification of Drug Resistant Candida auris
}

\author{
Milena Kordalewska* and David S. Perlin* \\ Center for Discovery and Innovation, Hackensack Meridian Health, Nutley, NJ, United States
}

Candida auris is a multidrug resistant yeast, recognized as a cause of invasive infections and health care associated outbreaks around the world. C. auris is of great public health concern, due to its propensity for drug resistance, mode and pace of its transmission, and the possibility that biologic and epidemiologic factors could exacerbate worldwide emergence of $C$. auris infections. Currently, outbreak response is complicated by limited treatment options and inadequate disinfection strategies, as well as by issues (misidentification, long turnaround time) associated with application of commonly used diagnostic tools. Misdiagnosis of $C$. auris is common since many diagnostic platforms available in clinical and public health laboratories depend on reference databases that have not fully incorporated $C$. auris. Moreover, the correlation between minimal inhibitory concentration values (MICs) and clinical outcomes is poorly understood resulting

OPEN ACCESS

Edited by:

Teun Boekhout,

Westerdijk Fungal Biodiversity Institute, Netherlands

Reviewed by:

Guillermo Quindós,

University of the Basque Country,

Spain

Ferry Hagen,

Westerdijk Fungal Biodiversity Institute, Netherlands

${ }^{*}$ Correspondence:

Milena Kordalewska

milena.kordalewska@hmh-cdi.org

David S. Perlin

david.perlin@hmh-cdi.org

Specialty section: This article was submitted to Fungi and Their Interactions,

a section of the journal

Frontiers in Microbiology

Received: 04 May 2019 Accepted: 05 August 2019 Published: 20 August 2019

Citation:

Kordalewska M and Perlin DS (2019) Identification of Drug Resistant

Candida auris.

Front. Microbiol. 10:1918. doi: 10.3389/fmicb.2019.01918 in the absence of $C$. auris-specific breakpoints. New, accurate and fast diagnostic methods have emerged to facilitate effective patient management and improve infection control measures, ultimately reducing the potential for $C$. auris transmission. This review provides an overview of available $C$. auris detection/identification and antifungal susceptibility determination methods and discusses their advantages and limitations. A special emphasis has been placed on culture-independent methods that have recently been developed and offer faster turnaround times.

Keywords: Candida, Candida auris, diagnostics, identification, detection, antifungal drug resistance

\section{INTRODUCTION}

Over the last few decades, fungal infections are increasingly recognized as a serious concern for human health, especially for immunocompromised patients and those hospitalized with serious underlying diseases. Candidemia and other forms of invasive candidiasis, including infections of normally sterile body fluids, deep tissues, and organs, are the most common nosocomial invasive fungal infections, and are associated with prolonged hospitalization and increased health care costs (Lockhart, 2014; Pfaller et al., 2019). In the US, the most often isolated species is Candida albicans, but a trend of increasing number of cases of infection with non-albicans Candida, thought to be driven largely by the increasing use of prophylactic antifungal agents such as fluconazole (Deorukhkar et al., 2014), has been reported. Strikingly, non-albicans Candida species have been associated with higher mortality and greater antifungal drug resistance than those seen with C. albicans infections (Pfaller et al., 2019).

As one of the most prominent emerged pathogens, Candida auris has been spreading across the globe causing hospital outbreaks (Meis and Chowdhary, 2018). It is often associated with high level antifungal drug resistance, which limits treatment options. It was first reported in 2009 after being isolated from an external ear canal discharge of a patient in Japan (Satoh et al., 2009). Subsequently, cases of persistent colonization and various types of invasive infections have been reported from many countries located on six continents (Table 1). Bloodstream infection has been 
the most frequently reported type of invasive infection, with mortality ranging from 30 to $60 \%$ (Chowdhary et al., 2017). However, C. auris isolates have been recovered from many other types of clinical specimens (Table 1). Currently, C. auris is divided into four major clades displaying distinct biological and drug resistance properties (Szekely et al., 2019; Welsh et al., 2019): I, South Asian; II, East Asian; III, South African; IV, South American. C. auris infections in other parts of the world, such as the United States and United Kingdom have been caused by strains that are genetically related to these clades (Table 1). Every major clade except for Clade II has been linked to outbreaks with invasive infections. A molecular epidemiological survey performed by Chow et al. in the US showed that travel-related cases, in which patients probably acquired $C$. auris through health-care exposures abroad, are not common (5/73 clinical cases) and that the current epidemic in the United States is dominated by Clade I and Clade IV. Genetic diversity among isolates from the same patients, health-care facilities, and states indicated local and ongoing transmission (however, no apparent transmission even between adjacent states, NY and NJ) (Chow et al., 2018). Several factors, including widespread antifungal use and climate change, have been recently discussed (Jackson et al., 2019), but the exact reasons why this fungus has started spreading in recent years remain unclear.

Major obstacles impacting the control of C. auris spread include common misidentification by diagnostic platforms available in clinical and public health laboratories, a poor understanding of resistance to antifungal drugs and disinfectants, and a high propensity to contaminate health care environments which results in transmission of clonal C. auris isolates (spread through contact with affected patients and contaminated surfaces). Ultimately, correct detection and identification of the pathogen and its antifungal susceptibility, followed by strict adherence to appropriate treatment and infection prevention and control strategies is crucial for limiting of the spread of $C$. auris.

The aim of this review is to provide an overview of available C. auris detection/identification and antifungal susceptibility determination methods and discuss their advantages and limitations. A special emphasis is put on molecular-based and culture-independent methods that have recently been developed and offer faster turnaround times.

\section{Candida auris IDENTIFICATION AND DETECTION IN CLINICAL SAMPLES}

There is a vast variety of fungal identification methods used by clinical and public health laboratories all over the world to detect C. auris. However, many of them use systems (e.g., VITEK 2, API 20C) for which misidentification with other yeasts has been reported (Table 1). Moreover, because much of the treatment for Candida infections is empirical, many institutions do not identify Candida to the species level, and if they do it, it is mostly for sterile-site isolates (Lockhart et al., 2017a; Durante et al., 2018). However, the worldwide emergence of $C$. auris heightened public health relevance of the identification of Candida to the species level. As broadly discussed by Lockhart et al., species should be determined for isolates recovered from invasive candidiasis cases and selected non-invasive isolates in order to improve detection of $C$. auris. Species identification of isolates from normally sterile body sites enables guidance for initial therapy considering predictable species-specific susceptibility. Moreover, given the emergence of $C$. auris, the Centers for Disease Control and Prevention (CDC) advises species-level identification in the following situations: (1) when clinically indicated in the care of a patient; (2) when a case of $C$. auris infection or colonization has been detected in a facility or unit; (3) when a patient has had an overnight stay in a health care facility in the previous 6 months in a country with $C$. auris transmission. Laboratories should also review past records to identify confirmed or suspected cases, as well as conduct prospective surveillance (Lockhart et al., 2017c).

Accurate identification of $C$. auris infection in the clinical laboratory can be problematic especially when relying on phenotypic characteristics. Institutions without appropriate methodology for C. auris species characterization or with isolates that are unidentified or suspect for $C$. auris are strongly advised to contact a reference laboratory for guidance (Durante et al., 2018). In the US, the CDC Advanced Molecular Detection (AMD) program ${ }^{1}$ addresses gaps in technology and workforce knowledge, helps build capacity and provides training at CDC, as well as state and local public health laboratories across the nation.

It is noteworthy, that $C$. auris identification inaccuracies still persist, which has complicated our understanding of the real global prevalence of infections caused by this yeast. Challenges in $C$. auris identification emphasize the importance of local and international collaboration between hospitals (care team), diagnostic laboratories, public health authorities and researchers to optimize diagnostic capacities for rapid identification of emerging pathogens (Lockhart et al., 2017c; Durante et al., 2018).

\section{Enrichment Culture Protocol for C. auris Colonization Screening}

The CDC, regional, and state public health laboratories in the United States use Salt Sabouraud Dulcitol enrichment broth procedure for isolation of $C$. auris from clinical skin swabs and environmental sponge surveillance samples. Welsh et al. recommended using dulcitol instead of dextrose as the main carbon source in order to decrease the opportunities of coincubation of other (non-target) species like C. glabrata and C. parapsilosis (Welsh et al., 2017).

When screening for $C$. auris colonization, laboratories receive swabs immersed in modified liquid Amies medium. An aliquot (usually $100 \mu \mathrm{l}$ ) of the vortexed swab medium is inoculated into Salt Sabouraud Dulcitol enrichment broth and incubated at $40^{\circ} \mathrm{C}$ (temperature selective for C. auris), with shaking at $250 \mathrm{rpm}$ for at least 5 days. Every sample that becomes turbid is streaked by a loop onto CHROMagar Candida. In a case when a sample remains clear, an aliquot is spread onto CHROMagar Candida. All CHROMagar Candida plates are incubated at $37^{\circ} \mathrm{C}$ for $48 \mathrm{~h}$ and screened for the presence of colony types possible for C. auris (Sexton et al., 2018b).

\footnotetext{
${ }^{1}$ www.cdc.gov/amd
} 
TABLE 1 | Published cases of Candida auris (as of April 01, 2019).

\begin{tabular}{|c|c|c|c|c|c|c|}
\hline Continent & Country & Clade & Isolates source & Reliable identification & $\begin{array}{l}\text { Cases of initial } \\
\text { misidentification }\end{array}$ & References \\
\hline \multirow[t]{15}{*}{ Asia } & China & N/A & $\begin{array}{l}\text { Blood, urine, catheter, sputum, } \\
\text { bronchoalveolar lavage fluid (BAL) }\end{array}$ & MALDI-TOF MS, rDNA sequencing & $\begin{array}{l}\text { C. haemulonii by VITEK 2; } \\
\text { C. famata by API } 20 C\end{array}$ & Tian et al., 2018; Wang et al., 2018 \\
\hline & India & 1 & $\begin{array}{l}\text { Blood, tissue, pus, BAL, catheter } \\
\text { tip, swab (axilla, groin, oral, rectal, } \\
\text { skin, vaginall), wound }\end{array}$ & MALDI-TOF MS, rDNA sequencing & $\begin{array}{l}\text { C. haemulonii, C. famata, C. } \\
\text { glabrata by VITEK 2; C. sake by } \\
\text { API 20C }\end{array}$ & $\begin{array}{l}\text { Chowdhary et al., 2013; Sarma } \\
\text { et al., 2013; Chowdhary et al., } \\
\text { 2014; Chatterjee et al., 2015; } \\
\text { Kathuria et al., 2015; Kumar et al., } \\
\text { 2015; Prakash et al., 2016; Sharma } \\
\text { et al., 2016; Lockhart et al., 2017b; } \\
\text { Rudramurthy et al., 2017; } \\
\text { Chowdhary et al., 2018; Mathur } \\
\text { et al., } 2018\end{array}$ \\
\hline & Iran & $N / A$ & Ear swab & MALDI-TOF MS, rDNA sequencing & No & Abastabar et al., 2019 \\
\hline & Israel & III & Blood, urine, wound, environment & $\begin{array}{l}\text { MALDI-TOF MS and rDNA } \\
\text { sequencing }\end{array}$ & $\begin{array}{l}\text { C. haemulonii by VITEK 2; } \\
\text { C. parapsilosis by BD Phoenix }\end{array}$ & $\begin{array}{l}\text { Ben-Ami et al., 2017; Belkin et al., } \\
2018\end{array}$ \\
\hline & Japan & $\|$ & Ear discharge & $\begin{array}{l}\text { MALDI-TOF MS and rDNA } \\
\text { sequencing }\end{array}$ & $\begin{array}{l}\text { C. haemulonii by VITEK 2; } \\
\text { Saccharomyces kluyveri by API } \\
\text { ID 32C }\end{array}$ & $\begin{array}{l}\text { Satoh et al., 2009; Iguchi et al., } \\
2018\end{array}$ \\
\hline & Kuwait & N/A & $\begin{array}{l}\text { Blood, urine, catheter tip, BAL, pus, } \\
\text { endotracheal aspirate, abdominal } \\
\text { drain fluid }\end{array}$ & $\begin{array}{l}\text { rDNA sequencing, C. auris-specific } \\
\text { PCR }\end{array}$ & C. haemulonii by VITEK 2 & $\begin{array}{l}\text { Emara et al., 2015; Khan et al., } \\
\text { 2018a; Khan et al., 2018b; Alobaid } \\
\text { and Khan, } 2019\end{array}$ \\
\hline & Malaysia & N/A & Blood & rDNA sequencing & $\begin{array}{l}\text { C. haemulonii by VITEK 2; } \\
\text { Rhodotorula glutinis by API 20C }\end{array}$ & Mohd Tap et al., 2018 \\
\hline & Oman & $\mathrm{N} / \mathrm{A}$ & Blood & MALDI-TOF MS & $\begin{array}{l}\text { C. haemulonii by API } 20 \mathrm{C} \text { and } \\
\text { BD Phoenix }\end{array}$ & $\begin{array}{l}\text { Al-Siyabi et al., 2017; Mohsin et al., } \\
2017\end{array}$ \\
\hline & Pakistan & । & Blood, urine, wound & MALDI-TOF MS & $\begin{array}{l}\text { Saccharomyces cerevisiae by } \\
\text { API } 20 \text { C }\end{array}$ & Lockhart et al., 2017b \\
\hline & Russia & 1 & Blood, urine, tracheal aspirate & MALDI-TOF MS & No & Barantsevich et al., 2019 \\
\hline & Saudi Arabia & । & Blood, pleural tissue & MALDI-TOF MS & C. haemulonii by VITEK 2 & Abdalhamid et al., 2018 \\
\hline & Singapore & $\mathrm{N} / \mathrm{A}$ & Blood, femur tissue & rDNA sequencing & No & Tan and Tan, 2018 \\
\hline & South Korea & $\|$ & $\begin{array}{l}\text { Blood, catheter tip, pelvic } \\
\text { Jackson-Pratt drain, ear discharge }\end{array}$ & MALDI-TOF MS, rDNA sequencing & C. haemulonii by VITEK 2 & $\begin{array}{l}\text { Lee et al., 2011; Choi et al., 2017; } \\
\text { Jung et al., 2019; Kwon et al., } \\
2019 \text { a }\end{array}$ \\
\hline & Taiwan & $N / A$ & Facial lesion & MALDI-TOF MS, rDNA sequencing & $\begin{array}{l}\text { C. haemulonii by VITEK } 2 \text { and } \\
\text { BD Phoenix }\end{array}$ & Tang et al., 2019 \\
\hline & $\begin{array}{l}\text { United Arab } \\
\text { Emirates }\end{array}$ & $\mathrm{N} / \mathrm{A}$ & Blood & MALDI-TOF MS & $\begin{array}{l}\text { C. haemulonii by VITEK 2; } \\
\text { negative result on BioFire's } \\
\text { Filmarray1 Blood Culture } \\
\text { Identification* }\end{array}$ & Alatoom et al., 2018 \\
\hline Africa & South Africa & III & $\begin{array}{l}\text { Blood, cerebrospinal fluid, serous } \\
\text { fluid, tissue, urine, respiratory tract } \\
\text { specimen, swab (skin, mucosal), } \\
\text { catheter tip }\end{array}$ & MALDI-TOF MS, rDNA sequencing & $\begin{array}{l}\text { C. haemulonii by VITEK } 2 \text {; } \\
\text { R. glutinis by API } 20 \mathrm{C}\end{array}$ & $\begin{array}{l}\text { Magobo et al., 2014; Prakash et al., } \\
\text { 2016; Lockhart et al., 2017b; } \\
\text { Govender et al., } 2018\end{array}$ \\
\hline
\end{tabular}


TABLE 1 | Continued

\begin{tabular}{|c|c|c|c|c|c|c|}
\hline Continent & Country & Clade & Isolates source & Reliable identification & $\begin{array}{l}\text { Cases of initial } \\
\text { misidentification }\end{array}$ & References \\
\hline \multirow{4}{*}{$\begin{array}{l}\text { South } \\
\text { America }\end{array}$} & Brazil & IV & Blood & MALDI-TOF MS, rDNA sequencing & No & Prakash et al., 2016 \\
\hline & Colombia & IV & $\begin{array}{l}\text { Blood, urine, cerebrospinal fluid, } \\
\text { peritoneal fluid, ocular secretion, } \\
\text { swab (axilla, groin, hands, rectum) } \\
\text { healthcare environment }\end{array}$ & MALDI-TOF MS, rDNA sequencing & $\begin{array}{l}\text { C. haemulonii by VITEK } 2 \text { and } \\
\text { BD Phoenix; C. tropicalis by } \\
\text { MicroScan Walkaway; } \\
\text { C. albicans, C. guilliermondii, C. } \\
\text { parapsilosis, C. catenulata, } \\
\text { Rhodotorula rubra by } \\
\text { MicroScan; C. famata by API } \\
\text { Candida }\end{array}$ & $\begin{array}{l}\text { Morales-Lopez et al., 2017; } \\
\text { Escandón et al., 2018; } \\
\text { Parra-Giraldo et al., 2018; } \\
\text { Escandón et al., } 2019\end{array}$ \\
\hline & Panama & IV & $\begin{array}{l}\text { Blood, urine, catheter tip, pleural } \\
\text { fluid }\end{array}$ & MALDI-TOF MS, rDNA sequencing & C. haemulonii by VITEK 2 & Arauz et al., 2018 \\
\hline & Venezuela & IV & Blood & rDNA sequencing & C. haemulonii by VITEK 2 & $\begin{array}{l}\text { Calvo et al., 2016; Lockhart et al., } \\
\text { 2017b }\end{array}$ \\
\hline \multirow{2}{*}{$\begin{array}{l}\text { North } \\
\text { America }\end{array}$} & Canada & N/A & Ear swab & MALDI-TOF MS & No & Schwartz and Hammond, 2017 \\
\hline & United States & I, II, III, IV & $\begin{array}{l}\text { Blood, urine, BAL, respiratory tract, } \\
\text { sputum, bile fluid, wound, catheter } \\
\text { tip, bone, ear, jejunal biopsy, swab } \\
\text { (axilla, groin, skin, nares), } \\
\text { environment }\end{array}$ & $\begin{array}{l}\text { MALDI-TOF MS, C. auris-specific } \\
\text { gPCR, rDNA sequencing }\end{array}$ & $\begin{array}{l}\text { Not identified by VITEK MS; } \\
\text { C. haemulonii by VITEK } 2\end{array}$ & $\begin{array}{l}\text { Azar et al., 2017; Tsay et al., 2017; } \\
\text { Vallabhaneni et al., 2017; Chow } \\
\text { et al., 2018; Leach et al., 2018; } \\
\text { Lesho et al., 2018; Park et al., } 2019\end{array}$ \\
\hline \multirow[t]{5}{*}{ Europe } & Austria & $\mathrm{N} / \mathrm{A}$ & Ear swab & MALDI-TOF MS, rDNA sequencing & $\begin{array}{l}\text { C. haemulonii, } C \text {. } \\
\text { duobushaemulonii by VITEK } 2\end{array}$ & Pekard-Amenitsch et al., 2018 \\
\hline & Belgium & $\mathrm{N} / \mathrm{A}$ & Blood & MALDI-TOF MS, rDNA sequencing & C. haemulonii by VITEK 2 & Dewaele et al., 2018 \\
\hline & Spain & Close to III & $\begin{array}{l}\text { Blood, urine, vascular line, } \\
\text { respiratory specimen, catheter tip, } \\
\text { swab (rectal), healthcare } \\
\text { environment }\end{array}$ & rDNA sequencing & $\begin{array}{l}\text { C. haemulonii, C. Iusitaniae by } \\
\text { VITEK MS; Saccharomyces } \\
\text { cerevisiae by AuxaColor 2; } \\
\text { C. sake by API 20C }\end{array}$ & $\begin{array}{l}\text { Ruiz Gaitan et al., 2017, } \\
\text { Ruiz-Gaitan A. et al., 2018; } \\
\text { Ruiz-Gaitan et al., } 2019\end{array}$ \\
\hline & Switzerland & N/A & $\begin{array}{l}\text { Tracheal aspirate, groin, auditory } \\
\text { canal, urine }\end{array}$ & MALDI-TOF MS, rDNA sequencing & No & Riat et al., 2018 \\
\hline & United Kingdom & I, II, III & $\begin{array}{l}\text { Blood, urine, sputum, cerebrospinal } \\
\text { fluid, shunt reservoirs, line, arterial } \\
\text { line, femoral line, pleural fluid, } \\
\text { cerebral tissue and fluid, catheter } \\
\text { tip, swab (groin, skin, oropharynx, } \\
\text { wound, pustule), hospital } \\
\text { environment }\end{array}$ & MALDI-TOF MS, rDNA sequencing & No & $\begin{array}{l}\text { Borman et al., 2016; Schelenz } \\
\text { et al., 2016; Borman et al., 2017; } \\
\text { Eyre et al., 2018; Rhodes et al., } \\
\text { 2018; Khatamzas et al., } 2019\end{array}$ \\
\hline Australia & & $11 I^{* *}$ & $\begin{array}{l}\text { Deep operative sternal bone } \\
\text { samples }\end{array}$ & $\begin{array}{l}\text { MALDI-TOF MS and rDNA } \\
\text { sequencing }\end{array}$ & No & Heath et al., 2019 \\
\hline
\end{tabular}

Countries within continents are listed in an alphabetical order. Clades: I, South Asian; II, East Asian; III, South African; IV, South American. rDNA sequencing: ITS and/or D1/D2 large subunit regions of rDNA sequencing.

N/A, information not available. *test detects only five common Candida species (C. albicans, C. glabrata, C. krusei, C. parapsilosis, and C. tropicalis). **a man from Kenya visiting Australia 


\section{Phenotypic and Biochemical Methods for $C$. auris Identification}

Candida auris isolates show smooth white to cream-colored colonies on Sabouraud dextrose agar and appear as beige to pink colonies on CHROMagar Candida medium. However, Bentz et al. (2018) described presence of alternate colors: pink, white, and sectored (dark purple) of smooth and glossy colonies (see photographs ${ }^{2}$ ), and phenotype switching in isolates recovered from swabs through enrichment broth procedure. By no means recovery of aforementioned colony types on CHROMagar Candida medium can be considered as final identification of C. auris, since other yeast, including C. parapsilosis, can look alike. Recovered colonies should be further analyzed by one of the reliable identification methods, e.g., rDNA sequencing, C. auris-specific PCR/qPCR, or MALDI-TOF MS.

Kumar et al. (2017) proposed using temperature tolerance and CHROMagar supplemented with Pal's medium in order to morphologically distinguish C. auris from C. haemulonii and C. duobushaemulonii. C. auris strains showed confluent growth of white to cream colored smooth colonies at $37^{\circ} \mathrm{C}$ and $42^{\circ} \mathrm{C}$ after 24 and $48 \mathrm{~h}$ incubation and did not produce pseudohyphae. Contrarily, isolates of the C. haemulonii complex showed poor growth of smooth, light-pink colonies at $24 \mathrm{~h}$ while at $48 \mathrm{~h}$ the growth was semiconfluent with the production of pseudohyphae (Kumar et al., 2017).

Candida auris has often been misidentified in conventional diagnostic laboratories using standard biochemical identification systems (Table 1), primarily due to the lack of C. auris references in their databases. As databases are being updated, accurate identification becomes more possible, like it happened with VITEK 28.01 software version (BioMérieux) in 2018 (Lockhart et al., 2017a; Govender et al., 2018), however misidentifications of strains from certain clades have been reported and all C. duobushaemulonii should be forwarded for further identification ${ }^{2}$. A high vigilance still needs to be in place when identification process results in $C$. haemulonii, $C$. duobushaemulonii, C. famata, C. glabrata from (not updated) VITEK 2 (bioMérieux), C. famata, C. sake, Rhodotorula glutinis, Saccharomyces cerevisiae from API 20C AUX (bioMérieux), C. haemulonii, C. parapsilosis, C. catenulata from BD Phoenix (Becton Dickinson), or C. albicans, C. parapsilosis, C. tropicalis, C. famata, C. lusitaniae, C. guilliermondii, C. catenulata, $R$. rubra from MicroScan (Beckman Coulter) (Lockhart et al., 2017a; Mizusawa et al., 2017). Consequently, it might be necessary to confirm such identification result, especially for high fluconazole minimal inhibitory concentration (MIC) or multidrug resistant isolates, by rDNA sequencing, C. aurisspecific PCR/qPCR or MALDI-TOF MS.

\section{Identification of $C$. auris by MALDI-TOF MS}

The matrix-assisted laser desorption ionization time-of-flight mass spectrometry (MALDI-TOF MS) can be used for rapid and accurate identification of microorganisms. MALDI-TOF

\footnotetext{
${ }^{2}$ www.cdc.gov/fungal/candida-auris/recommendations.html
}

MS generates characteristic mass spectra, unique for each microorganism, that can be used as their fingerprints. Since the identification process is based on comparison of spectra acquired for a tested sample and a database of spectra of know species, accurate result is reliant on the presence of the sample organism spectrum in the database. That is why absence of identification or misidentification of fungal species by MALDI-TOF MS is essentially due to absence, mistakes or incomplete reference spectra in the database (Croxatto et al., 2012).

Lack of proper spectra in the databases has resulted in the misidentification of C. auris as C. haemulonii and C. albicans, among others, by MALDI-TOF MS (Kim et al., 2016; Wattal et al., 2017). However, once research-use only (RUO) or manufacturer's databases are updated with $C$. auris and related species spectra, MALDI-TOF MS identification of $C$. auris to the species level appears to be accurate (Table 1 and Cendejas-Bueno et al., 2012; Girard et al., 2016; Bao et al., 2018; Vatanshenassan et al., 2019). It is crucial that laboratories review the presence of aforementioned spectra in the database and confirm the laboratory detection capacity by testing a panel of reference strains, e.g., "Candida auris Panel” offered by CDC \& FDA Antibiotic Resistance (AR) Isolate $\mathrm{Bank}^{3}$, which contains C. auris isolates from all clades and other yeast species that are related to $C$. auris or are commonly misidentified as C. auris.

Evaluated the viability of $C$. auris after various MALDITOF MS extraction protocols (on-plate extraction, quick tube extraction, and extended tube extraction) to determine if isolates processing may expose laboratory workers to infectious agents. C. auris was effectively killed in all three methods. Additionally, the authors recommended use of the quick tube extraction method since it gave confidence scores not significantly different from the extended one but better than the on-plate method (Sterkel et al., 2018).

In general, compared with conventional identification methods, MALDI-TOF MS has been shown to confer a significant gain of both technician working time (pre-analytical procedure to prepare samples) and turnaround time (automated analytical procedure to obtain results). MALDI-TOF MS is suitable for high-throughput and rapid microbial identification at low costs and is an alternative for conventional laboratory biochemical and molecular identification systems. Even though the running costs are significantly cheaper than those of conventional identification methods (Croxatto et al., 2012), the amount of money required to purchase a MALDI-TOF MS instrument itself is often an obstacle for laboratories, ultimately preventing implementation of the technique.

In summary, the use of MALDI-TOF MS for the identification of clinically relevant yeasts, including C. auris, is rapid and accurate providing that the database is constructed with a comprehensive collection of accurately identified reference strains. Currently, accurate identification of $C$. auris can be achieved by using freely available MicrobeNet database validated by CDC experts ${ }^{4}$ or the following MALDI-TOF MS systems: Bruker Biotyper with FDA-approved MALDI Biotyper CA

\footnotetext{
${ }^{3}$ www.cdc.gov/drugresistance/resistance-bank

${ }^{4}$ www.cdc.gov/microbenet
} 
System library (Version Claim 4) or their "research use only" libraries (Versions 2014 [5627] and more recent) and VITEK (MALDI-TOF) MS RUO (with Saramis Ver 4.14 database and Saccharomycetaceae update).

\section{Molecular-Based Methods for C. auris Identification}

Molecular techniques have greatly enhanced the diagnosis of causal agents of infectious disease, particularly when the causal agent is difficult to culture and identify. Sequencing of genetic loci and PCR/qPCR assays have successfully been applied for identification of $C$. auris (Table 1). Especially real-time PCR assays bear incomparable potential of being the most efficient tool for high-throughput screening of surveillance samples. If properly validated, they can deliver the diagnostic result within several hours, since the DNA can be isolated directly from the patient specimen without the need of obtaining a colony.

\section{Sequencing of Genetic Loci}

Sequencing of rDNA genetic loci, namely internal transcribed spacer and D1/D2 region of large subunit (LSU), that are amplified with standard primers, provides accurate identification of $C$. auris and differentiation from other yeast (Table 1). However, as mentioned by Lockhart et al. sequencing is not routinely used to determine isolate species, since the cost, technical demands, and lengthy turnaround times for those without in-house sequencing capacity can make this technique unsuitable for some laboratories (Lockhart et al., 2017a).

It is also worth to mention, that comparative analysis of rDNA sequences should not be used to define relations between strains due to its insufficient discriminatory power, as revised elsewhere (Jeffery-Smith et al., 2018).

\section{Nucleic Acid-Based Identification Strategies}

Various molecular-based assays, from conventional PCR, through real-time PCR, to more complex T2 magnetic resonance or Loop-mediated Isothermal Amplification (LAMP), have been developed, that can be applied based on the available resources (Table 2). Most of the assays have the ability to provide rapid results - within several hours from the clinical sample delivery. In comparison, other methods, including biochemical automated systems and MALDI-TOF MS, require culture, that can take anywhere from 4 to 14 days.

Most of the developed assays are highly sensitive, with a detection limit of 1-10 C. auris CFU/PCR reaction (Table 2). More importantly, the assays are highly specific and no crossreactivity is observed with all known closely and distantly related yeasts and other pathogens. Currently, at least three assays have been successfully validated on a panel of clinical swabs (Leach et al., 2018; Sexton et al., 2018a,b), which included samples that were negative for $C$. auris DNA but harbored other organisms. No cross-reactivity was observed, further confirming the high specificity of the assays that can be used for direct detection of $C$. auris without a need of prior culture. It is a huge progress from the status quo of axilla/groin composite swabs processing (see: 2.1 Enrichment culture protocol for colonization screening). The delay generated by the requirement of culture has been dramatically limiting the opportunity to quickly respond to outbreaks.

Nucleic acid-based identification strategies may have several technical (availability of equipment and separation of sample prep/amplification/analysis areas) and cost (equipment, reagents) limitations depending on the laboratory infrastructure. Another aspect may be considered both a benefit or limitation, depending on the aim of particular study: DNA from both live and dead $C$. auris cells can be detected, which can be a discrepancy with culture, but shouldn't be considered a false positive result. A positive result from a non-sterile specimen (skin swab, environmental sponge) is an indicator of past or present C. auris colonization.

\section{DETECTION OF C. auris ANTIFUNGAL DRUG RESISTANCE}

Antifungal susceptibility testing (AFST) for C. auris has been performed using various standardized tests, including Clinical and Laboratory Standards Institute (CLSI) and European Committee on Antimicrobial Susceptibility Testing (EUCAST) broth microdilution methods, the $E$-test gradient diffusion method, and the VITEK 2 antifungal susceptibility system. However, analysis of susceptibility testing results for an emerging fungal species like $C$. auris is complicated by the limited understanding of the correlation between MICs and clinical outcomes (no established breakpoints enabling AFST result interpretation). Currently, CDC provides guidance for C. auris MIC interpretation, that based on information gathered for related Candida species and expert opinion ${ }^{5}$.

Nevertheless, C. auris isolates are often characterized by reduced susceptibility to azoles, polyenes, and echinocandins. Results of susceptibility testing performed on Indian isolates revealed their nearly universal resistance to fluconazole. For that reason, $C$. auris was initially suspected to be intrinsically resistant to this azole drug (Chowdhary et al., 2014, 2018; Kathuria et al., 2015; Arendrup et al., 2017). Moreover, reduced susceptibility of $C$. auris to other triazole antifungal drugs, including voriconazole, posaconazole, itraconazole, and isavuconazole was reported (Chowdhary et al., 2014; Arendrup et al., 2017; BenAmi et al., 2017; Lockhart et al., 2017b; Morales-Lopez et al., 2017; Vallabhaneni et al., 2017; Khan et al., 2018a; Rhodes et al., 2018; Ruiz-Gaitan et al., 2019). Such situation when reduced susceptibility to azole class drugs is commonly observed is extremely worrying, since azoles are a mainstay in the treatment of Candida infections and antifungals other than fluconazole might be unavailable in resource-limited countries. Nowadays, as more susceptibility information has become available for isolates from around the world and fluconazole susceptible isolates (2-8 mg/l MIC) have been reported, it is believed that fluconazole resistance is an acquired phenomenon in C. auris (Lockhart et al., 2017a). Furthermore, polyene antifungal drug amphotericin B can show variable activity against C. auris isolates (Shin et al., 2012; Sarma et al., 2013; Magobo et al., 2014;

${ }^{5}$ www.cdc.gov/fungal/candida-auris/c-auris-antifungal.html 
TABLE 2 | Molecular-based methods for identification and detection of Candida auris.

\begin{tabular}{|c|c|c|c|c|c|c|}
\hline Paper & Purpose & Identification from & DNA extraction & Assay type & Assay specificity & Detection limit \\
\hline $\begin{array}{l}\text { Kordalewska et al., } \\
2017\end{array}$ & New assay & Colonies & $\begin{array}{l}\text { Quick boiling method } \\
\text { (Brillowska-Dabrowska et al., 2010) }\end{array}$ & PCR and APCR (SYBR Green) & $\begin{array}{l}\text { (1)C. auris (PCR and qPCR) } \\
\text { (2)C. auris, } \\
\text { C. duobushaemulonii, } \\
\text { C. haemulonii, and C. Iusitaniae } \\
\text { (qPCR) }\end{array}$ & $\begin{array}{l}\text { (1) } 10 \mathrm{CFU} / \mathrm{rxn} \\
\text { (2) } 1000 \mathrm{CFU} / \mathrm{rxn}\end{array}$ \\
\hline Sexton et al., 2018b & $\begin{array}{l}\text { Validation of the } \\
\text { assay }\end{array}$ & Clinical swabs & $\begin{array}{l}\text { Bead beating and DNeasy } \\
\text { PowerLyzer Microbial Kit (Qiagen) }\end{array}$ & $\begin{array}{l}\text { qPCR (SYBR Green) from } \\
\text { Kordalewska et al., } 2017\end{array}$ & C. auris & 4 CFU/rxn \\
\hline Leach et al., 2018 & New assay & $\begin{array}{l}\text { Clinical swabs, } \\
\text { environmental sponges }\end{array}$ & Bead beating & qPCR (TaqMan) & C. auris & $1 \mathrm{CFU} / \mathrm{rxn}$ \\
\hline Ahmad et al., 2019 & $\begin{array}{l}\text { Validation of rapid } \\
\text { extraction method }\end{array}$ & Clinical swabs & MagNA Pure 96 (Roche) & $\begin{array}{l}\text { qPCR (TaqMan) from Leach et al., } \\
2018\end{array}$ & C. auris & $1 \mathrm{CFU} / 10 \mu \mathrm{l}$ \\
\hline Theill et al., 2018 & New assay & Colonies & N/A & Duplex PCR & C. auris and C. haemulonii & N/A \\
\hline Arastehfar et al., 2018 & New assay & Colonies & CTAB method (Gupta et al., 2004) & Tetraplex PCR & $\begin{array}{l}\text { C. auris, C. haemulonii, } \\
\text { C. duobushaemulonii, and } \\
\text { C. pseudohaemulonii, }\end{array}$ & $\mathrm{N} / \mathrm{A}$ \\
\hline $\begin{array}{l}\text { Ruiz-Gaitan A.C. et al., } \\
2018\end{array}$ & New assay & Colonies & Boiling in $20 \mathrm{mM} \mathrm{NaOH}$ & Duplex PCR & C. auris & N/A \\
\hline Khan et al., 2018a & New assay & Colonies & $\begin{array}{l}\text { Rapid method using Chelex-100 } \\
\text { (Asadzadeh et al., 2015) }\end{array}$ & PCR & C. auris & $\mathrm{N} / \mathrm{A}$ \\
\hline $\begin{array}{l}\text { Martinez-Murcia et al., } \\
2018\end{array}$ & $\begin{array}{l}\text { Validation of a } \\
\text { commercial kit }\end{array}$ & Colonies & $\begin{array}{l}\text { MagNA Lyser with green beads } \\
\text { followed by MagNA Pure } 96 \\
\text { (Roche); or GPS DNAcol }\end{array}$ & GPS MONODOSE dtec-qPCR kit & C. auris & $5 \mathrm{CFU} / \mathrm{rxn}$ \\
\hline Arastehfar et al., 2019a & New assay & $\begin{array}{l}\text { Colonies, spiked serum } \\
\text { samples }\end{array}$ & CTAB method (Gupta et al., 2004) & $\begin{array}{l}\text { Tetraplex qPCR (SYBR } \\
\text { Green/EvaGreen) }\end{array}$ & $\begin{array}{l}\text { C. auris, C. haemulonii, } \\
\text { C. duobushaemulonii, and } \\
\text { C. pseudohaemulonii, }\end{array}$ & $10 \mathrm{CFU}$ \\
\hline Arastehfar et al., 2019b & New assay & Colonies & $\begin{array}{l}\text { DNeasy Blood \& Tissue Kit (Qiagen) } \\
\text { with modifications }\end{array}$ & Multiplex PCR & 21 species including C. auris & $\mathrm{N} / \mathrm{A}$ \\
\hline Sexton et al., 2018a & $\begin{array}{l}\text { Validation of a } \\
\text { commercial assay }\end{array}$ & Clinical swabs & T2Dx & $\begin{array}{l}\text { T2 Magnetic Resonance (T2MR) } \\
\text { system }\end{array}$ & C. auris & $5 \mathrm{CFU} / \mathrm{ml}$ \\
\hline Yamamoto et al., 2018 & New assay & $\begin{array}{l}\text { Colonies, clinical ear } \\
\text { swab, mock } \\
\text { environmental samples }\end{array}$ & $\begin{array}{l}\text { Boiling in water (colonies) or } \\
\text { Kaneka Easy DNA Extraction kit } \\
\text { version } 2 \text { (KANEKA Co.) (swabs } \\
\text { and environmental samples) }\end{array}$ & $\begin{array}{l}\text { Loop mediated isothermal } \\
\text { amplification (LAMP) }\end{array}$ & C. auris & $20 \mathrm{CFU} / \mathrm{rxn}$ \\
\hline
\end{tabular}

N/A, information not available. rxn, reaction. 
Calvo et al., 2016; Prakash et al., 2016; Sharma et al., 2016; Lockhart et al., 2017b; Vallabhaneni et al., 2017; Khan et al., 2018a; Rhodes et al., 2018; Escandón et al., 2019; Ruiz-Gaitan et al., 2019). The concern about resistance to azoles and amphotericin $\mathrm{B}$ has led to the recommendation for the use of echinocandins as a first-line therapy (Chowdhary et al., 2016; Public Health England, 2017). However, reports of C. auris isolates showing elevated MIC to one or more echinocandins have been published (Chowdhary et al., 2014, 2018; Sharma et al., 2016; Arendrup et al., 2017; Lockhart et al., 2017b; Vallabhaneni et al., 2017; Kordalewska et al., 2018; Rhodes et al., 2018). Strikingly, some $C$. auris isolates have demonstrated reduced susceptibility to multiple classes of antifungal agents, raising the possibility of pan-drug resistance (Kathuria et al., 2015; Lockhart et al., 2017b).

\section{Broth Microdilution Methods}

As already mentioned, at present, there are no antifungal clinical breakpoints reported for C. auris by CLSI or EUCAST. Tentative epidemiological cut off values (ECVs) were proposed in a recent study, where MIC distributions of 123 clinical C. auris isolates from India were analyzed (Arendrup et al., 2017). The ECV, which defines the upper limit of the wild type susceptible population of clinical isolates, provides a measure of potential drug resistance. Determined ECVs are valuable in the analysis of MICs of isolates from the South Asian clade, yet their application to isolates from other clades may lead to incorrect estimation of potential drug resistance, since there are strong indications that MIC distributions can vary substantially for C. auris isolates from different clades (Szekely et al., 2019; Welsh et al., 2019).

We reported a significant challenge with obtaining an accurate AFST MIC readout for caspofungin since all tested isolates exhibited an Eagle effect (also known as the paradoxical growth effect), with the intensities of the Eagle effect varying among the isolates (Kordalewska et al., 2018). However, echinocandins were effective in vivo in the treatment of invasive murine candidiasis caused by $C$. auris isolates, despite the presence of the Eagle effect in vitro and only determinant impacting the pharmacodynamic response was the FKS1 genotype. Therefore, as with many Candida species, standardized CLSI susceptibility testing with caspofungin should be viewed cautiously or avoided since an Eagle effect results in an overestimation of the resistant population (Kordalewska et al., 2018).

Nearly all laboratories rely on automated systems for routine AFST. These systems are attractive because they can reduce the laboratory workload relative to manual broth microdilution methods, but they often underperform. Although Kwon et al. observed essential (96.7\%) agreement between VITEK 2 and CLSI methods in fluconazole AFST (Kwon et al., 2019b), others have reported its suboptimal performance for amphotericin B (Kathuria et al., 2015), and a cautionary approach is warranted for automated AFST systems.

Therefore, an analysis of susceptibility results obtained by phenotypic tests is not always straightforward and may have difficulties defining susceptible or resistant isolates. More knowledge about clade-specific susceptibility patterns (MICs distribution) is crucial to support the global effort to fight C. auris infections efficiently.

\section{MALDI-TOF}

The MALDI Biotyper antibiotic susceptibility test-rapid assay (MBT ASTRA) for rapid AFST. C. auris cells were inoculated into RPMI 1640 with 2-fold serial dilutions of echinocandins (anidulafungin, micafungin, and caspofungin) and incubated at $37^{\circ} \mathrm{C}$ with shaking for $6 \mathrm{~h}$. Later the cells were washed, lysed and deposited in a grid together with matrix, and spectra were acquired and analyzed. A comparison between MBT ASTRA and the CLSI broth microdilution assay results detected a sensitivity and specificity of $100 \%$ and $98 \%$ for anidulafungin, and 100 and $95.5 \%$ for micafungin, respectively. A categorical agreement of $98 \%$ and $96 \%$ was calculated for the two methods. For caspofungin, sensitivity and specificity of 100 and $73 \%$ were found, respectively, with a categorical agreement of $82 \%$. MBT ASTRA has a potential to detect echinocandin non-susceptible C. auris isolates within $6 \mathrm{~h}$, which makes it a promising candidate for AFST in clinical laboratories in the future (Vatanshenassan et al., 2019).

\section{Molecular-Based Methods}

Availability of methods for rapid and accurate identification of $C$. auris antifungal drug resistance is of urgent need. Molecular-based tests have the potential to become part of the clinical laboratory routine for resistance detection to help direct therapy and enhance epidemiological surveillance. Since azole and echinocandin resistance in $C$. auris are closely associated with specific ERG11 and FKS1 mutations, respectively (Healey et al., 2018; Kordalewska et al., 2018), their analysis can deliver a valuable information on antifungal drug resistance, and facilitate implementation of effective antifungal therapy. Regretfully, at this time there is no clear explanation for the molecular mechanism of $C$. auris amphotericin B resistance. The role of non-synonymous mutations in a transcription factor similar to FLO8 or membrane transporter described by Escandón et al. (2019) needs to be further investigated. It is also possible that the mechanism of amphotericin B resistance is not mutation-based but regulated at the transcription level (Munoz et al., 2018).

\section{Genetic Basis of C. auris Antifungal Drug Resistance}

Several groups have sequenced genes encoding targets for azoles (Chowdhary et al., 2018; Healey et al., 2018; Kwon et al., 2019b) and echinocandins (Berkow and Lockhart, 2018; Chowdhary et al., 2018; Kordalewska et al., 2018), while the others performed whole genome sequencing (WGS) (Lockhart et al., 2017b; Rhodes et al., 2018), that led to the discovery of mutations responsible for $C$. auris resistance. Echinocandin resistance is mediated through limited mutations S639P (Berkow and Lockhart, 2018) or S639F (Chowdhary et al., 2018; Kordalewska et al., 2018) in FKS1, and 
azole resistance through F126L, Y132F, and K143R in ERG11 (Lockhart et al., 2017b; Healey et al., 2018; Rhodes et al., 2018). To date, these are the only mutations associated with clinical failures due to azole and echinocandin drugs.

It is crucial to remember that not all mutations detected in target genes confer resistance, and some mutations e.g., the ones leading to K177R, N335S, and E343D amino acid substitutions in Erg11, likely represent genetically evolved clade differences, and do not contribute to any decrease in drug susceptibility (Healey et al., 2018). Any newly identified allele should be carefully investigated to resolve its potential involvement in drug resistance. Validation of resistance properties can be done through molecular engineering approaches (creating/repairing mutation in an organism of the same species, cloning a mutated allele into a model organism) and pharmacodynamic studies in animals.

Moreover, as discussed earlier (see section "Sequencing of Genetic Loci"), and even more accurate for WGS, several factors related to the cost, turnaround time, technology and expertise make sequencing impractical for the regular workflow of clinical microbiology laboratories (Lockhart et al., 2017a).

\section{Real-Time PCR Assay for Identification of Mutations in C. auris ERG11 and FKS1 Genes}

Recently, highly accurate real-time PCR diagnostic platform was developed for rapid identification of mutations in C. auris ERG11 and FKS1 genes, conferring azole and echinocandin resistance, respectively. Analysis of melting profiles of molecular beacons, small stem-loop-structured DNA oligonucleotides, was used in conjunction with asymmetric PCR. Since a singlestranded amplicon is generated during asymmetric PCR, the molecular beacon can anneal and generate fluorescence at low temperature. Later, the temperature is increased, and the probe slowly dissociates from the target, which results in the fluorescence intensity decrease. Melting curve analysis (a plot of the fluorescence intensity changes as a function of temperature) enables determination of temperature at which the molecular beacon-target DNA hybrids melt apart $\left(T_{m}\right)$. The $T_{m}$ value is different in a situation when the target and the probe sequences match perfectly and when they are mismatched, thereby providing an ideal tool for typing single-nucleotide polymorphisms e.g., wild-type (WT)/non-WT discrimination (Zhao et al., 2016).

A duplex ERG11 assay and a simplex FKS1 HS1 assay were developed to identify the most prominent resistance-associated mutations (Y132F and K143R in ERG11; S639F in FKS1 HS1) within $2 \mathrm{~h}$. The molecular diagnostic results from the assays were $100 \%$ concordant with DNA sequencing results. Advantages of the assays include easy interpretation of the results since the testing strain can be easily identified by comparing the $T_{m}$ value with those generated by reference strains representing

\section{REFERENCES}

Abastabar, M., Haghani, I., Ahangarkani, F., Rezai, M. S., Taghizadeh Armaki, M., Roodgari, S., et al. (2019). Candida auris otomycosis in Iran and review of recent literature. Mycoses 62, 101-105. doi: 10.1111/myc.12886
WT and mutant target region; multiplex potential by combining several probes; and expandable readiness for novel/unreported mutation detection, because the assay will be able to pick up a novel mutation by simply incorporating the corresponding genotype into the library without the need for assay redesign (Hou et al., 2019).

This platform may potentially be used for direct detection of $C$. auris antifungal drug resistance markers in clinical swabs, dramatically reducing the time needed to obtain information on isolate susceptibility. Thus, it has the potential to overcome the deficiencies of existing in vitro susceptibility-based assays to identify azole- and/or echinocandin-resistant C. auris and holds promise as a surrogate diagnostic method to direct antifungal therapy more effectively.

\section{CONCLUSION}

Efforts to control C. auris have posed multiple challenges that include developing and evaluating new diagnostics, understanding its epidemiology, and identifying means to minimize transmission among patients. With emergence of less common fungal opportunists, newly described species, and species that can exhibit antifungal resistance mechanisms, one must take care to not blindly accept results from commonly available methods. New molecular methods used in tandem with classical methods give the diagnostician a broad and everincreasing armamentarium at their disposal to provide the clinician with the most reliable information to ensure the best possible patient care and outcome.

\section{AUTHOR CONTRIBUTIONS}

MK contributed to the conceptualization and writing the original draft of the manuscript. DP contributed to the reviewing and editing of the manuscript.

\section{FUNDING}

This work was supported by the CDC's investments to combat antibiotic resistance under the contract number 200-2017-96195 (BAA FY2017-OADS-01) to DP.

\section{ACKNOWLEDGMENTS}

We thank Drs. Yanan Zhao, Cristina Jiménez-Ortigosa, Erika Shor, and Kelley Healey, and other members of the DP lab for helpful discussions. of Candida auris infections from Saudi Arabia. J. Infect. Public Health 11, 598-599. doi: 10.1016/j.jiph.2018.05.010

Ahmad, A., Spencer, J. E., Lockhart, S. R., Singleton, S., Petway, D. J., Bagarozzi, D. A. Jr., et al. (2019). A high-throughput and rapid method for accurate 
identification of emerging multidrug-resistant Candida auris. Mycoses 62, 513-518. doi: 10.1111/myc.12907

Alatoom, A., Sartawi, M., Lawlor, K., AbdelWareth, L., Thomsen, J., Nusair, A., et al. (2018). Persistent candidemia despite appropriate fungal therapy: first case of Candida auris from the United Arab Emirates. Int. J. Infect. Dis. 70, 36-37. doi: 10.1016/j.ijid.2018.02.005

Alobaid, K., and Khan, Z. (2019). Epidemiologic characteristics of adult candidemic patients in a secondary hospital in Kuwait: a retrospective study. J. Mycol. Med. 29, 35-38. doi: 10.1016/j.mycmed.2018.12.001

Al-Siyabi, T., Al Busaidi, I., Balkhair, A., Al-Muharrmi, Z., Al-Salti, M., and Al'Adawi, B. (2017). First report of Candida auris in Oman: clinical and microbiological description of five candidemia cases. J. Infect. 75, 373-376. doi: 10.1016/j.jinf.2017.05.016

Arastehfar, A., Fang, W., Badali, H., Vaezi, A., Jiang, W., Liao, W., et al. (2018). Low-cost tetraplex PCR for the global spreading multi-drug resistant fungus, Candida auris and its phylogenetic relatives. Front. Microbiol. 9:1119. doi: 10. 3389/fmicb.2018.01119

Arastehfar, A., Fang, W., Daneshnia, F., Al-Hatmi, A. M., Liao, W., Pan, W., et al. (2019a). Novel multiplex real-time quantitative PCR detecting system approach for direct detection of Candida auris and its relatives in spiked serum samples. Future Microbiol. 14, 33-45. doi: 10.2217/fmb-2018-0227

Arastehfar, A., Fang, W., Pan, W., Lackner, M., Liao, W., Badiee, P., et al. (2019b). YEAST PANEL multiplex PCR for identification of clinically important yeast species: stepwise diagnostic strategy, useful for developing countries. Diagn. Microbiol. Infect. Dis. 93, 112-119. doi: 10.1016/j.diagmicrobio.2018.09.007

Arauz, A. B., Caceres, D. H., Santiago, E., Armstrong, P., Arosemena, S., Ramos, C., et al. (2018). Isolation of Candida auris from 9 patients in Central America: importance of accurate diagnosis and susceptibility testing. Mycoses 61, 44-47. doi: $10.1111 /$ myc. 12709

Arendrup, M. C., Prakash, A., Meletiadis, J., Sharma, C., and Chowdhary, A. (2017). Comparison of EUCAST and CLSI reference microdilution MICs of eight antifungal compounds for Candida auris and associated tentative epidemiological cutoff values. Antimicrob. Agents Chemother. 61:e00485-17. doi: 10.1128/AAC.00485-17

Asadzadeh, M., Ahmad, S., Hagen, F., Meis, J. F., Al-Sweih, N., and Khan, Z. (2015). Simple, low-cost detection of Candida parapsilosis complex isolates and molecular fingerprinting of Candida orthopsilosis strains in Kuwait by ITS region sequencing and amplified fragment length polymorphism analysis. PLoS One 10:e0142880. doi: 10.1371/journal.pone.0142880

Azar, M. M., Turbett, S. E., Fishman, J. A., and Pierce, V. M. (2017). Donor-derived transmission of Candida auris during lung transplantation. Clin. Infect. Dis. 65, 1040-1042. doi: 10.1093/cid/cix460

Bao, J. R., Master, R. N., Azad, K. N., Schwab, D. A., Clark, R. B., Jones, R. S., et al. (2018). Rapid, accurate identification of Candida auris by using a novel matrix-assisted laser desorption ionization-time of flight mass spectrometry (MALDI-TOF MS) database (library). J. Clin. Microbiol. 56:e01700-17.

Barantsevich, N. E., Orlova, O. E., Shlyakhto, E. V., Johnson, E. M., Woodford, N., Lass-Floerl, C., et al. (2019). Emergence of Candida auris in Russia. J. Hosp. Infect. 102, 445-448. doi: 10.1016/j.jhin.2019.02.021

Belkin, A., Gazit, Z., Keller, N., Ben-Ami, R., Wieder-Finesod, A., Novikov, A., et al. (2018). Candida auris infection leading to nosocomial transmission, Israel, 2017. Emerg. Infect. Dis. 24, 801-804. doi: 10.3201/eid2404.171715

Ben-Ami, R., Berman, J., Novikov, A., Bash, E., Shachor-Meyouhas, Y., Zakin, S., et al. (2017). Multidrug-resistant Candida haemulonii and C. auris, Tel Aviv, Israel. Emerg. Infect. Dis. 23, 195-203. doi: 10.3201/eid2302.161486

Bentz, M. L., Sexton, D. J., Welsh, R. M., and Litvintseva, A. P. (2018). Phenotypic switching in newly emerged multidrug-resistant pathogen Candida auris. Med. Mycol. doi: 10.1093/mmy/myy100 [Epub ahead of print].

Berkow, E. L., and Lockhart, S. R. (2018). Activity of CD101, a long-acting echinocandin, against clinical isolates of Candida auris. Diagn. Microbiol. Infect. Dis. 90, 196-197. doi: 10.1016/j.diagmicrobio.2017.10.021

Borman, A. M., Szekely, A., and Johnson, E. M. (2016). Comparative pathogenicity of united kingdom isolates of the emerging pathogen Candida auris and other key pathogenic Candida species. mSphere 1:e00189-16. doi: 10.1128/mSphere. 00189-16

Borman, A. M., Szekely, A., and Johnson, E. M. (2017). Isolates of the emerging pathogen Candida auris present in the UK have several geographic origins. Med. Mycol. 55, 563-567. doi: 10.1093/mmy/myw147
Brillowska-Dabrowska, A., Nielsen, S. S., Nielsen, H. V., and Arendrup, M. C. (2010). Optimized 5-hour multiplex PCR test for the detection of tinea unguium: performance in a routine PCR laboratory. Med. Mycol. 48, 828-831. doi: 10.3109/13693780903531579

Calvo, B., Melo, A. S., Perozo-Mena, A., Hernandez, M., Francisco, E. C., Hagen, F., et al. (2016). First report of Candida auris in America: clinical and microbiological aspects of 18 episodes of candidemia. J. Infect. 73, 369-374. doi: 10.1016/j.jinf.2016.07.008

Cendejas-Bueno, E., Kolecka, A., Alastruey-Izquierdo, A., Theelen, B., Groenewald, M., Kostrzewa, M., et al. (2012). Reclassification of the Candida haemulonii complex as Candida haemulonii (C. haemulonii group I), C. duobushaemulonii sp. nov. (C. haemulonii group II), and C. haemulonii var. vulnera var. nov.: three multiresistant human pathogenic yeasts. J. Clin. Microbiol. 50, 3641-3651. doi: 10.1128/JCM.02248-12

Chatterjee, S., Alampalli, S. V., Nageshan, R. K., Chettiar, S. T., Joshi, S., and Tatu, U. S. (2015). Draft genome of a commonly misdiagnosed multidrug resistant pathogen Candida auris. BMC Genomics 16:686. doi: 10.1186/s12864015-1863-z

Choi, H. I., An, J., Hwang, J. J., Moon, S. Y., and Son, J. S. (2017). Otomastoiditis caused by Candida auris: case report and literature review. Mycoses 60, 488-492. doi: $10.1111 /$ myc. 12617

Chow, N. A., Gade, L., Tsay, S. V., Forsberg, K., Greenko, J. A., Southwick, K. L., et al. (2018). Multiple introductions and subsequent transmission of multidrugresistant Candida auris in the USA: a molecular epidemiological survey. Lancet Infect. Dis. 18, 1377-1384. doi: 10.1016/S1473-3099(18)30597-8

Chowdhary, A., Anil Kumar, V., Sharma, C., Prakash, A., Agarwal, K., Babu, R., et al. (2014). Multidrug-resistant endemic clonal strain of Candida auris in India. Eur. J. Clin. Microbiol. Infect. Dis. 33, 919-926. doi: 10.1007/s10096-0132027-1

Chowdhary, A., Prakash, A., Sharma, C., Kordalewska, M., Kumar, A., Sarma, S., et al. (2018). A multicentre study of antifungal susceptibility patterns among 350 Candida auris isolates (2009-17) in India: role of the ERG11 and FKS1 genes in azole and echinocandin resistance. J. Antimicrob. Chemother. 73, 891-899. doi: $10.1093 / \mathrm{jac} / \mathrm{dkx} 480$

Chowdhary, A., Sharma, C., Duggal, S., Agarwal, K., Prakash, A., Singh, P. K., et al. (2013). New clonal strain of Candida auris, Delhi, India. Emerg. Infect. Dis. 19, 1670-1673. doi: 10.3201/eid1910.130393

Chowdhary, A., Sharma, C., and Meis, J. F. (2017). Candida auris: a rapidly emerging cause of hospital-acquired multidrug-resistant fungal infections globally. PLoS Pathog. 13:e1006290. doi: 10.1371/journal.ppat.1006290

Chowdhary, A., Voss, A., and Meis, J. F. (2016). Multidrug-resistant Candida auris: 'new kid on the block' in hospital-associated infections? J. Hosp. Infect. 94, 209-212. doi: 10.1016/j.jhin.2016.08.004

Croxatto, A., Prod'hom, G., and Greub, G. (2012). Applications of MALDI-TOF mass spectrometry in clinical diagnostic microbiology. FEMS Microbiol. Rev. 36, 380-407. doi: 10.1111/j.1574-6976.2011.00298.x

Deorukhkar, S. C., Saini, S., and Mathew, S. (2014). Non-albicans Candida infection: an emerging threat. Interdiscip. Perspect. Infect. Dis. 2014:615958. doi: $10.1155 / 2014 / 615958$

Dewaele, K., Frans, J., Smismans, A., Ho, E., Tollens, T., and Lagrou, K. (2018). First case of Candida auris infection in Belgium in a surgical patient from Kuwait. Acta Clin. Belg. doi: 10.1080/17843286.2018.1555114 [Epub ahead of print].

Durante, A. J., Maloney, M. H., Leung, V. H., Razeq, J. H., and Banach, D. B. (2018). Challenges in identifying Candida auris in hospital clinical laboratories: a need for hospital and public health laboratory collaboration in rapid identification of an emerging pathogen. Infect. Control Hosp. Epidemiol. 39, 1015-1016. doi: 10.1017/ice.2018.133

Emara, M., Ahmad, S., Khan, Z., Joseph, L., Al-Obaid, I., Purohit, P., et al. (2015). Candida auris candidemia in Kuwait, 2014. Emerg. Infect. Dis. 21, 1091-1092. doi: 10.3201/eid2106.150270

Escandón, P., Caceres, D. H., Espinosa-Bode, A., Rivera, S., Armstrong, P., Vallabhaneni, S., et al. (2018). Notes from the field: surveillance for Candida auris - Colombia, September 2016-May 2017. MMWR Morb. Mortal. Wkly. Rep. 67, 459-460. doi: 10.15585/mmwr.mm6715a6

Escandón, P., Chow, N. A., Caceres, D. H., Gade, L., Berkow, E. L., Armstrong, P., et al. (2019). Molecular epidemiology of Candida auris in Colombia reveals a highly related, countrywide colonization with regional patterns in amphotericin B resistance. Clin. Infect. Dis. 68, 15-21. doi: 10.1093/cid/ciy411 
Eyre, D. W., Sheppard, A. E., Madder, H., Moir, I., Moroney, R., Quan, T. P., et al. (2018). A Candida auris outbreak and its control in an intensive care setting. N. Engl. J. Med. 379, 1322-1331. doi: 10.1056/NEJMoa171 4373

Girard, V., Mailler, S., Chetry, M., Vidal, C., Durand, G., van Belkum, A., et al. (2016). Identification and typing of the emerging pathogen Candida auris by matrix-assisted laser desorption ionisation time of flight mass spectrometry. Mycoses 59, 535-538. doi: 10.1111/myc.12519

Govender, N. P., Magobo, R. E., Mpembe, R., Mhlanga, M., Matlapeng, P., Corcoran, C., et al. (2018). Candida auris in South Africa, 2012-2016. Emerg. Infect. Dis. 24, 2036-2040. doi: 10.3201/eid2411.180368

Gupta, A. K., Boekhout, T., Theelen, B., Summerbell, R., and Batra, R. (2004). Identification and typing of Malassezia species by amplified fragment length polymorphism and sequence analyses of the internal transcribed spacer and large-subunit regions of ribosomal DNA. J. Clin. Microbiol. 42, 4253-4260. doi: 10.1128/JCM.42.9.4253-4260.2004

Healey, K. R., Kordalewska, M., Jimenez Ortigosa, C., Singh, A., Berrio, I., Chowdhary, A., et al. (2018). Limited ERG11 mutations identified in isolates of Candida auris directly contribute to reduced azole susceptibility. Antimicrob. Agents Chemother. 62:e01427-18. doi: 10.1128/AAC.01427-18

Heath, C. H., Dyer, J. R., Pang, S., Coombs, G. W., and Gardam, D. J. (2019). Candida auris sternal osteomyelitis in a man from Kenya visiting Australia, 2015. Emerg. Infect. Dis. 25, 192-194. doi: 10.3201/eid2501.181321

Hou, X., Lee, A., Jimenez-Ortigosa, C., Kordalewska, M., Perlin, D. S., and Zhao, Y. (2019). Rapid detection of ERG11-associated azole resistance and FKS-associated echinocandin resistance in Candida auris. Antimicrob. Agents Chemother. 63:e01811-18. doi: 10.1128/AAC.01811-18

Iguchi, S., Mizushima, R., Kamada, K., Itakura, Y., Yoshida, A., Uzawa, Y., et al. (2018). The second Candida auris isolate from aural discharge in Japan. Jpn. J. Infect. Dis. 71, 174-175. doi: 10.7883/yoken.JJID.2017.466

Jackson, B. R., Chow, N., Forsberg, K., Litvintseva, A. P., Lockhart, S. R., Welsh, R., et al. (2019). On the origins of a species: what might explain the rise of Candida auris? J. Fungi 5:58. doi: 10.3390/jof5030058

Jeffery-Smith, A., Taori, S. K., Schelenz, S., Jeffery, K., Johnson, E. M., Borman, A., et al. (2018). Candida auris: a review of the literature. Clin. Microbiol. Rev. 31:e00029-17. doi: 10.1128/CMR.00029-17

Jung, J., Kim, M. J., Kim, J. Y., Lee, J. Y., Kwak, S. H., Hong, M. J., et al. (2019). Candida auris colonization or infection of the ear: a single-center study in South Korea from 2016 to 2018. Med. Mycol. doi: 10.1093/mmy/myz020 [Epub ahead of print].

Kathuria, S., Singh, P. K., Sharma, C., Prakash, A., Masih, A., Kumar, A., et al. (2015). Multidrug-resistant Candida auris misidentified as Candida haemulonii: characterization by matrix-assisted laser desorption ionizationtime of flight mass spectrometry and DNA sequencing and its antifungal susceptibility profile variability by Vitek 2, CLSI broth microdilution, and Etest method. J. Clin. Microbiol. 53, 1823-1830. doi: 10.1128/JCM.003 67-15

Khan, Z., Ahmad, S., Al-Sweih, N., Joseph, L., Alfouzan, W., and Asadzadeh, M. (2018a). Increasing prevalence, molecular characterization and antifungal drug susceptibility of serial Candida auris isolates in Kuwait. PLoS One 13:e195743. doi: 10.1371/journal.pone.0195743

Khan, Z., Ahmad, S., Benwan, K., Purohit, P., Al-Obaid, I., Bafna, R., et al. (2018b). Invasive Candida auris infections in Kuwait hospitals: epidemiology, antifungal treatment and outcome. Infection 46, 641-650. doi: 10.1007/s15010-018$1164-y$

Khatamzas, E., Madder, H., and Jeffery, K. (2019). Neurosurgical device-associated infections due to Candida auris - Three cases from a single tertiary center. J. Infect. 78, 409-421. doi: 10.1016/j.jinf.2019.02.004

Kim, T. H., Kweon, O. J., Kim, H. R., and Lee, M. K. (2016). Identification of uncommon Candida species using commercial identification systems. J. Microbiol. Biotechnol. 26, 2206-2213. doi: 10.4014/jmb.1609.09012

Kordalewska, M., Lee, A., Park, S., Berrio, I., Chowdhary, A., Zhao, Y., et al. (2018). Understanding echinocandin resistance in the emerging pathogen Candida auris. Antimicrob. Agents Chemother. 62:e00238-18. doi: 10.1128/AAC.002 38-18

Kordalewska, M., Zhao, Y., Lockhart, S. R., Chowdhary, A., Berrio, I., and Perlin, D. S. (2017). Rapid and accurate molecular identification of the emerging multidrug-resistant pathogen Candida auris. J. Clin. Microbiol. 55, 2445-2452. doi: 10.1128/JCM.00630-17

Kumar, A., Sachu, A., Mohan, K., Vinod, V., Dinesh, K., and Karim, S. (2017). Simple low cost differentiation of Candida auris from Candida haemulonii complex using CHROMagar Candida medium supplemented with Pal's medium. Rev. Iberoam. Micol. 34, 109-111. doi: 10.1016/j.riam.2016.11.004

Kumar, D., Banerjee, T., Pratap, C. B., and Tilak, R. (2015). Itraconazole-resistant Candida auris with phospholipase, proteinase and hemolysin activity from a case of vulvovaginitis. J. Infect. Dev. Ctries. 9, 435-437. doi: 10.3855/jidc.4582

Kwon, Y. J., Shin, J. H., Byeon, S. A., Choi, M. J., Won, E. J., Lee, D., et al. (2019a). Candida auris clinical isolates from South Korea: identification, antifungal susceptibility, and genotyping. J. Clin. Microbiol. 57:e01624-18.

Kwon, Y. J., Shin, J. H., Byun, S. A., Choi, M. J., Won, E. J., Lee, D., et al. (2019b). Candida auris clinical isolates from South Korea: identification, antifungal susceptibility, and genotyping. J. Clin. Microbiol. 57:e01624-18.

Leach, L., Zhu, Y., and Chaturvedi, S. (2018). Development and validation of a realtime PCR assay for rapid detection of Candida auris from surveillance samples. J. Clin. Microbiol. 56:e01223-17. doi: 10.1128/JCM.01223-17

Lee, W. G., Shin, J. H., Uh, Y., Kang, M. G., Kim, S. H., Park, K. H., et al. (2011). First three reported cases of nosocomial fungemia caused by Candida auris. J. Clin. Microbiol. 49, 3139-3142. doi: 10.1128/JCM.00319-11

Lesho, E. P., Bronstein, M. Z., McGann, P., Stam, J., Kwak, Y., Maybank, R., et al. (2018). Importation, mitigation, and genomic epidemiology of Candida auris at a large teaching hospital. Infect. Control Hosp. Epidemiol. 39, 53-57. doi: $10.1017 /$ ice.2017.231

Lockhart, S. R. (2014). Current epidemiology of Candida infection. Clin. Microbiol. Newsl. 36, 131-136. doi: 10.1016/j.clinmicnews.2014.08.001

Lockhart, S. R., Berkow, E. L., Chow, N., and Welsh, R. M. (2017a). Candida auris for the clinical microbiology laboratory: not your grandfather's Candida species. Clin. Microbiol. Newsl. 39, 99-103. doi: 10.1016/j.clinmicnews.2017.06.003

Lockhart, S. R., Etienne, K. A., Vallabhaneni, S., Farooqi, J., Chowdhary, A., Govender, N. P., et al. (2017b). Simultaneous emergence of multidrug-resistant Candida auris on 3 continents confirmed by whole-genome sequencing and epidemiological analyses. Clin. Infect. Dis. 64, 134-140. doi: 10.1093/cid/ciw691

Lockhart, S. R., Jackson, B. R., Vallabhaneni, S., Ostrosky-Zeichner, L., Pappas, P. G., and Chiller, T. (2017c). Thinking beyond the common Candida species: need for species-level identification of Candida due to the emergence of multidrug-resistant Candida auris. J. Clin. Microbiol. 55, 3324-3327. doi: 10. 1128/JCM.01355-17

Magobo, R. E., Corcoran, C., Seetharam, S., and Govender, N. P. (2014). Candida auris-associated candidemia, South Africa. Emerg. Infect. Dis. 20, 1250-1251. doi: $10.3201 /$ eid2007.131765

Martinez-Murcia, A., Navarro, A., Bru, G., Chowdhary, A., Hagen, F., and Meis, J. F. (2018). Internal validation of GPS() MONODOSE CanAur dtec-qPCR kit following the UNE/EN ISO/IEC 17025:2005 for detection of the emerging yeast Candida auris. Mycoses 61, 877-884. doi: 10.1111/myc.12834

Mathur, P., Hasan, F., Singh, P. K., Malhotra, R., Walia, K., and Chowdhary, A. (2018). Five-year profile of candidaemia at an Indian trauma centre: high rates of Candida auris blood stream infections. Mycoses 61, 674-680. doi: 10.1111/ myc. 12790

Meis, J. F., and Chowdhary, A. (2018). Candida auris: a global fungal public health threat. Lancet Infect. Dis. 18, 1298-1299. doi: 10.1016/s1473-3099(18)30609-1

Mizusawa, M., Miller, H., Green, R., Lee, R., Durante, M., Perkins, R., et al. (2017). Can multidrug-resistant Candida auris be reliably identified in clinical microbiology laboratories? J. Clin. Microbiol. 55, 638-640. doi: 10.1128/jcm. 02202-16

Mohd Tap, R., Lim, T. C., Kamarudin, N. A., Ginsapu, S. J., Abd Razak, M. F., Ahmad, N., et al. (2018). A fatal case of Candida auris and Candida tropicalis candidemia in neutropenic patient. Mycopathologia 183, 559-564. doi: 10.1007/ s11046-018-0244-y

Mohsin, J., Hagen, F., Al-Balushi, Z. A. M., de Hoog, G. S., Chowdhary, A., Meis, J. F., et al. (2017). The first cases of Candida auris candidaemia in Oman. Mycoses 60, 569-575. doi: 10.1111/myc.12647

Morales-Lopez, S. E., Parra-Giraldo, C. M., Ceballos-Garzon, A., Martinez, H. P., Rodriguez, G. J., Alvarez-Moreno, C. A., et al. (2017). Invasive infections with multidrug-resistant yeast Candida auris, Colombia. Emerg. Infect. Dis. 23, 162-164. doi: 10.3201/eid2301.161497 
Munoz, J. F., Gade, L., Chow, N. A., Loparev, V. N., Juieng, P., Berkow, E. L., et al. (2018). Genomic insights into multidrug-resistance, mating and virulence in Candida auris and related emerging species. Nat. Commun. 9:5346. doi: 10.1038/s41467-018-07779-6

Park, J. Y., Bradley, N., Brooks, S., Burney, S., and Wassner, C. (2019). Management of patients with Candida auris fungemia at community hospital, Brooklyn, New York, USA, 2016-2018(1). Emerg. Infect. Dis. 25, 601-602. doi: 10.3201/ eid2503.180927

Parra-Giraldo, C. M., Valderrama, S. L., Cortes-Fraile, G., Garzon, J. R., Ariza, B. E., Morio, F., et al. (2018). First report of sporadic cases of Candida auris in Colombia. Int. J. Infect. Dis. 69, 63-67. doi: 10.1016/j.ijid.2018.01.034

Pekard-Amenitsch, S., Schriebl, A., Posawetz, W., Willinger, B., Kolli, B., and Buzina, W. (2018). Isolation of Candida auris from ear of otherwise healthy patient, Austria, 2018. Emerg. Infect. Dis. 24, 1596-1597. doi: 10.3201/eid2408. 180495

Pfaller, M. A., Diekema, D. J., Turnidge, J. D., Castanheira, M., and Jones, R. N. (2019). Twenty years of the SENTRY antifungal surveillance program: results for Candida species from 1997-2016. Open Forum Infect. Dis. 6(Suppl. 1), S79-S94. doi: 10.1093/ofid/ofy358

Prakash, A., Sharma, C., Singh, A., Kumar Singh, P., Kumar, A., Hagen, F., et al. (2016). Evidence of genotypic diversity among Candida auris isolates by multilocus sequence typing, matrix-assisted laser desorption ionization timeof-flight mass spectrometry and amplified fragment length polymorphism. Clin. Microbiol. Infect. 22, 277.e1-277.e9. doi: 10.1016/j.cmi.2015.10.022

Public Health England, (2017). Guidance for the Laboratory Investigation, Management and Infection Prevention and Control for Cases of Candida auris. London: Public Health England.

Rhodes, J., Abdolrasouli, A., Farrer, R. A., Cuomo, C. A., Aanensen, D. M., Armstrong-James, D., et al. (2018). Genomic epidemiology of the UK outbreak of the emerging human fungal pathogen Candida auris. Emerg. Microbes Infect. 7:43. doi: 10.1038/s41426-018-0045-x

Riat, A., Neofytos, D., Coste, A., Harbarth, S., Bizzini, A., Grandbastien, B., et al. (2018). First case of Candida auris in Switzerland: discussion about preventive strategies. Swiss Med. Wkly. 148:w14622. doi: 10.4414/smw.2018. 14622

Rudramurthy, S. M., Chakrabarti, A., Paul, R. A., Sood, P., Kaur, H., Capoor, M. R., et al. (2017). Candida auris candidaemia in Indian ICUs: analysis of risk factors. J. Antimicrob. Chemother. 72, 1794-1801. doi: 10.1093/jac/dkx034

Ruiz Gaitan, A. C., Moret, A., Lopez Hontangas, J. L., Molina, J. M., Aleixandre Lopez, A. I., Cabezas, A. H., et al. (2017). Nosocomial fungemia by Candida auris: first four reported cases in continental Europe. Rev. Iberoam. Micol. 34, 23-27. doi: 10.1016/j.riam.2016.11.002

Ruiz-Gaitan, A., Moret, A. M., Tasias-Pitarch, M., Aleixandre-Lopez, A. I., Martinez-Morel, H., Calabuig, E., et al. (2018). An outbreak due to Candida auris with prolonged colonisation and candidaemia in a tertiary care European hospital. Mycoses 61, 498-505. doi: 10.1111/myc.12781

Ruiz-Gaitan, A. C., Fernandez-Pereira, J., Valentin, E., Tormo-Mas, M. A., Eraso, E., Peman, J., et al. (2018). Molecular identification of Candida auris by PCR amplification of species-specific GPI protein-encoding genes. Int. J. Med. Microbiol. 308, 812-818. doi: 10.1016/j.ijmm.2018.06.014

Ruiz-Gaitan, A. C., Canton, E., Fernandez-Rivero, M. E., Ramirez, P., and Peman, J. (2019). Outbreak of Candida auris in Spain: a comparison of antifungal activity by three methods with published data. Int. J. Antimicrob. Agents 53, 541-546. doi: 10.1016/j.ijantimicag.2019.02.005

Sarma, S., Kumar, N., Sharma, S., Govil, D., Ali, T., Mehta, Y., et al. (2013). Candidemia caused by amphotericin B and fluconazole resistant Candida auris. Indian J. Med. Microbiol. 31, 90-91.

Satoh, K., Makimura, K., Hasumi, Y., Nishiyama, Y., Uchida, K., and Yamaguchi, H. (2009). Candida auris sp. nov., a novel ascomycetous yeast isolated from the external ear canal of an inpatient in a Japanese hospital. Microbiol. Immunol. 53, 41-44. doi: 10.1111/j.1348-0421.2008.00 083. $\mathrm{x}$

Schelenz, S., Hagen, F., Rhodes, J. L., Abdolrasouli, A., Chowdhary, A., Hall, A., et al. (2016). First hospital outbreak of the globally emerging Candida auris in a European hospital. Antimicrob. Resist. Infect. Control 5:35. doi: 10.1186/s13756016-0132-5
Schwartz, I. S., and Hammond, G. W. (2017). First reported case of multidrugresistant Candida auris in Canada. Can. Commun. Dis. Rep. 43, 150-153. doi: 10.14745/ccdr.v43i78a02

Sexton, D. J., Bentz, M. L., Welsh, R. M., and Litvintseva, A. P. (2018a). Evaluation of a new T2 Magnetic Resonance assay for rapid detection of emergent fungal pathogen Candida auris on clinical skin swab samples. Mycoses 61, 786-790. doi: $10.1111 /$ myc. 12817

Sexton, D. J., Kordalewska, M., Bentz, M. L., Welsh, R. M., Perlin, D. S., and Litvintseva, A. P. (2018b). Direct detection of emergent fungal pathogen Candida auris in clinical skin swabs by SYBR green-based quantitative PCR assay. J. Clin. Microbiol. 56:e01337-18. doi: 10.1128/JCM.013 37-18

Sharma, C., Kumar, N., Pandey, R., Meis, J. F., and Chowdhary, A. (2016). Whole genome sequencing of emerging multidrug resistant Candida auris isolates in India demonstrates low genetic variation. New Microbes New Infect. 13, 77-82. doi: 10.1016/j.nmni.2016.07.003

Shin, J. H., Kim, M. N., Jang, S. J., Ju, M. Y., Kim, S. H., Shin, M. G., et al. (2012). Detection of amphotericin B resistance in Candida haemulonii and closely related species by use of the Etest, Vitek-2 yeast susceptibility system, and CLSI and EUCAST broth microdilution methods. J. Clin. Microbiol. 50, 1852-1855. doi: 10.1128/JCM.06440-11

Sterkel, A., Bateman, A., Valley, A., and Warshauer, D. (2018). Viability of Candida auris and other Candida species after various matrix-assisted laser desorption ionization-time of flight (MALDI-TOF) mass spectrometry-based extraction protocols. J. Clin. Microbiol. 56:e00886-18.

Szekely, A., Borman, A. M., and Johnson, E. M. (2019). Candida auris isolates of the Southern Asian and South African lineages exhibit different phenotypic and antifungal susceptibility profiles in vitro. J. Clin. Microbiol. 57:e02055-18. doi: 10.1128/JCM.02055-18

Tan, Y. E., and Tan, A. L. (2018). Arrival of Candida auris fungus in Singapore: report of the first 3 cases. Ann. Acad. Med. Singapore 47, $260-262$.

Tang, H. J., Lai, C. C., Lai, F. J., Li, S. Y., Liang, H. Y., and Hsueh, P. R. (2019). Emergence of multidrug-resistant Candida auris in Taiwan. Int. J. Antimicrob. Agents 53, 705-706. doi: 10.1016/j.ijantimicag.2019.02.011

Theill, L., Dudiuk, C., Morales-Lopez, S., Berrio, I., Rodriguez, J. Y., Marin, A., et al. (2018). Single-tube classical PCR for Candida auris and Candida haemulonii identification. Rev. Iberoam. Micol. 35, 110-112. doi: 10.1016/j.riam.2018. 01.003

Tian, S., Rong, C., Nian, H., Li, F., Chu, Y., Cheng, S., et al. (2018). First cases and risk factors of super yeast Candida auris infection or colonization from Shenyang, China. Emerg. Microbes Infect. 7:128. doi: 10.1038/s41426-0180131-0

Tsay, S., Welsh, R. M., Adams, E. H., Chow, N. A., Gade, L., Berkow, E. L., et al. (2017). Notes from the field: ongoing transmission of Candida auris in health care facilities - United States, June 2016-May 2017. MMWR Morb. Mortal. Wkly. Rep. 66, 514-515. doi: 10.15585/mmwr.mm6619a7

Vallabhaneni, S., Kallen, A., Tsay, S., Chow, N., Welsh, R., Kerins, J., et al. (2017). Investigation of the first seven reported cases of Candida auris, a globally emerging invasive, multidrug-resistant fungus-United States, May 2013-August 2016. Am. J. Transplant. 17, 296-299. doi: 10.1111/ajt. 14121

Vatanshenassan, M., Boekhout, T., Meis, J. F., Berman, J., Chowdhary, A., Ben-Ami, R., et al. (2019). Candida auris identification and rapid antifungal susceptibility testing against echinocandins by MALDITOF MS. Front. Cell. Infect. Microbiol. 9:20. doi: 10.3389/fcimb.2019. 00020

Wang, X., Bing, J., Zheng, Q., Zhang, F., Liu, J., Yue, H., et al. (2018). The first isolate of Candida auris in China: clinical and biological aspects. Emerg. Microbes Infect. 7:93. doi: 10.1038/s41426-0180095-0

Wattal, C., Oberoi, J. K., Goel, N., Raveendran, R., and Khanna, S. (2017). Matrix-assisted laser desorption ionization time of flight mass spectrometry (MALDI-TOF MS) for rapid identification of micro-organisms in the routine clinical microbiology laboratory. Eur. J. Clin. Microbiol. Infect. Dis. 36, 807-812. doi: 10.1007/s10096-016-2864-9 
Welsh, R. M., Bentz, M. L., Shams, A., Houston, H., Lyons, A., Rose, L. J., et al. (2017). Survival, persistence, and isolation of the emerging multidrugresistant pathogenic yeast Candida auris on a plastic health care surface. J. Clin. Microbiol. 55, 2996-3005. doi: 10.1128/JCM.00921-17

Welsh, R. M., Sexton, D. J., Forsberg, K., Vallabhaneni, S., and Litvintseva, A. (2019). Insights into the unique nature of the East Asian clade of the emerging pathogenic yeast Candida auris. J. Clin. Microbiol. 57:e00007-19. doi: 10.1128/ JCM.00007-19

Yamamoto, M., Alshahni, M. M., Tamura, T., Satoh, K., Iguchi, S., Kikuchi, K., et al. (2018). Rapid detection of Candida auris based on loop-mediated isothermal amplification (LAMP). J. Clin. Microbiol. 56:e00591-18.

Zhao, Y., Nagasaki, Y., Kordalewska, M., Press, E. G., Shields, R. K., Nguyen, M. H., et al. (2016). Rapid detection of FKSassociated echinocandin resistance in Candida glabrata. Antimicrob. Agents Chemother. 60, 6573-6577. doi: 10.1128/AAC.015 $74-16$
Conflict of Interest Statement: DP receives funding from the U.S. National Institutes of Health and contracts with The Centers for Disease Control and Prevention, Amplyx, Astellas, Cidara, and Scynexis. He serves on advisory boards for Amplyx, Astellas, Cidara, Matinas, N8 Medical and Scynexis. In addition, DP has an issued U.S. patent concerning echinocandin resistance.

The remaining author declares that the research was conducted in the absence of any commercial or financial relationships that could be construed as a potential conflict of interest.

Copyright $\odot 2019$ Kordalewska and Perlin. This is an open-access article distributed under the terms of the Creative Commons Attribution License (CC BY). The use, distribution or reproduction in other forums is permitted, provided the original author(s) and the copyright owner(s) are credited and that the original publication in this journal is cited, in accordance with accepted academic practice. No use, distribution or reproduction is permitted which does not comply with these terms. 